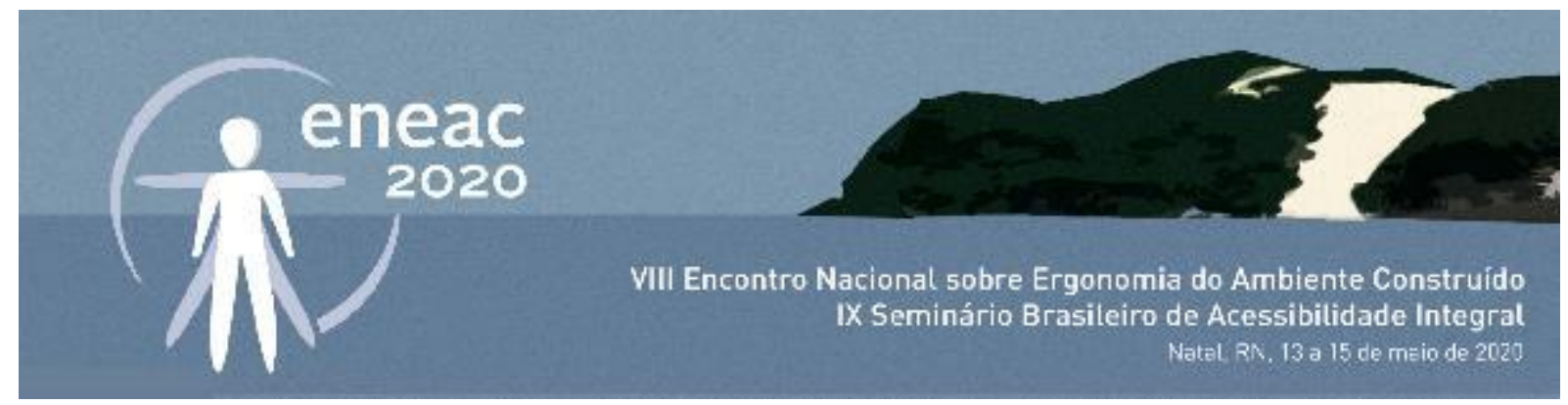

\title{
Fluxogramas de processo de projeto com parâmetros do desenho universal
}

\author{
Project process flowchart with universal design parameters
}

\begin{abstract}
EVANDRA RAMOS VICTORIO
Arquiteta e Urbanista, Doutoranda e Mestra em Arquitetura Tecnologia e Cidades, Faculdade de Engenharia Civil, Arquitetura e Urbanismo - FEC, Unicamp, evandra@robertoleme.com
\end{abstract}

JOÃO PEDRO SARTORATO NOZELA

Arquiteto e Urbanista, Estudante Especial da Faculdade de Engenharia Civil, Arquitetura e Urbanismo - FEC, Unicamp, na disciplina de Desenho Universal AQ-050, joaopedronozela@outlook.com

ÉRICA DA COSTA URBANO DE OLIVEIRA

Arquiteta e Urbanista, Mestra em Arquitetura Tecnologia e Cidades, Faculdade de Engenharia Civil, Arquitetura e Urbanismo - FEC, Unicamp, arquiteta.ericaurbano@gmail.com

NÚBIA BERNARDI

Arquiteta e Urbanista, Docente na Faculdade de Engenharia Civil, Arquitetura e Urbanismo - FEC, Unicamp,nubiab@unicamp.br

\section{RESUMO}

Este artigo apresenta uma discussão sobre a importância de diagramas e fluxogramas como ferramentas para o desenvolvimento de projeto arquitetônico, tendo como parâmetro os conceitos do Desenho Universal. Objetivou-se explorar questões de acessibilidade locomotora no decorrer do processo de projeto em arquitetura. Acredita-se que a acessibilidade para os usuários com diferentes graus de habilidades e necessidades é importante, e se observa que as deficiências locomotoras se destacam na literatura. Para este estudo, foi selecionada a tipologia de edifício cultural, pela diversidade de público e de atividades a serem oferecidas. Diante dos dados coletados, foi possível organizar um passo a passo em fluxograma que atua como guia para projetos arquitetônicos de edifícios culturais, contribuindo para boas práticas acadêmicas e profissionais na inclusão da acessibilidade. Este fluxograma de projeto aqui apresentado colocou como protagonista o conceito do Desenho Universal e a participação intrínseca dos usuários não apenas nas etapas preliminares, mas em outros momentos do processo, como consultores das decisões propostas pelo corpo técnico de projeto.

PALAVRAS-CHAVE: Desenho Universal; acessibilidade locomotora; processo de projeto; fluxograma. 


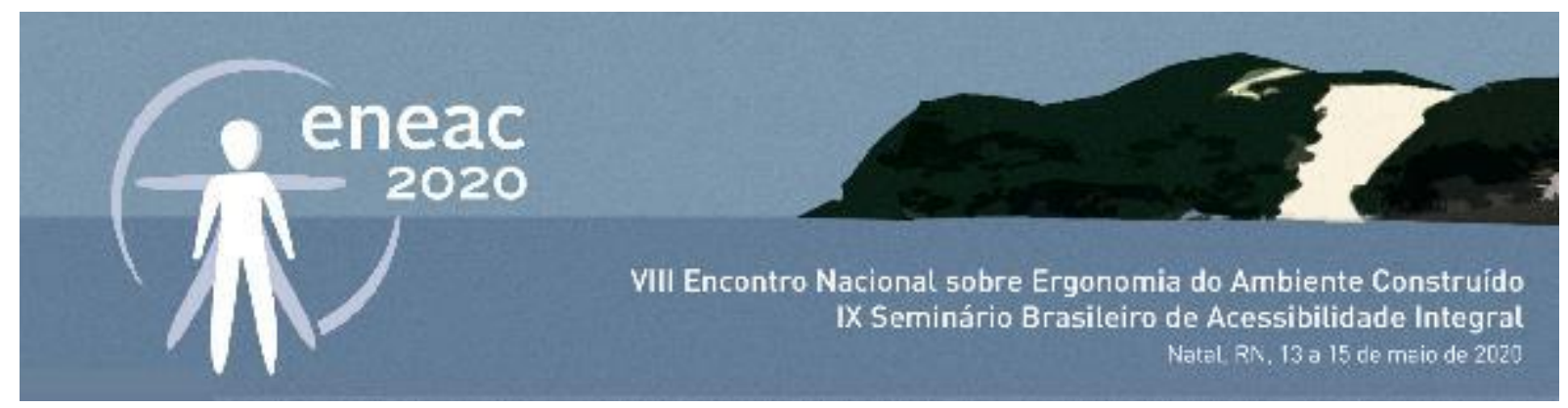

\begin{abstract}
This article presents a discussion about the importance of diagrams and flowcharts as tools for the development of architectural design, taking Universal Design concepts as a parameter. The objective was to explore locomotor accessibility issues during the architectural design process. It is believed that accessibility for users with different degrees of skills and needs is important, and it is observed that locomotor deficiencies stand out in the literature. For this study, the typology of cultural building was selected, due to the diversity of public and activities to be offered. Given the data collected, it was possible to organize a step-by-step flowchart that acts as a guide for architectural projects for cultural buildings, contributing to good academic and professional practices in the inclusion of accessibility. This project flowchart presented here placed the concept of Universal Design as the protagonist and the intrinsic participation of users not only in the preliminary stages, but in other moments of the process, as consultants of the decisions proposed by the project's technical staff.
\end{abstract}

KEYWORDS: Universal Design; locomotive accessibility; process design; flowchart.

\title{
1 INTRODUÇÃO
}

O exercício do projeto de arquitetura se tornou mais abrangente e complexo no cenário atual com as mudanças sociais, tecnológicas e econômicas. Os programas arquitetônicos se ampliaram, tornaramse mais complexos e com necessidades de maior responsabilidade ambiental, social e de trabalhos interdisciplinares (VICTORIO, 2019). Além destes fatores, as questões de acessibilidade como apresentadas na ABNT NBR 9050/2015 (ABNT, 2015), e os preceitos do Desenho Universal, devem ser incluídos nas primeiras fases do processo projetual.

O Desenho Universal (D.U) - termo empregado por Ron Mace e um grupo de signatários do Center of Universal Design (MACE et al, 1991), pode ser definido como um projeto inclusivo, voltado para a diversidade humana, e envolve a concepção de produtos, ambientes, elementos espaciais, programas e serviços a serem usados por todas as pessoas, sem necessidade de adaptação ou de projeto específico (integração e inclusão). Está fundamentado em sete princípios, a seguir: Uso equitativo (Pode ser usado por todos com segurança privacidade e conforto; elimina a segregação); Uso flexível (Atende a uma grande parte das preferências e habilidades das pessoas); Uso simples e intuitivo (Uso de fácil compreensão, dispensando experiência ou conhecimento por parte das pessoas); Informação de fácil percepção (Legível e redundante a apresentação de informações vitais); Tolerância ao erro (Minimiza os riscos e consequenciais de ações acidentais ou não intencionais); Baixo esforço físico (Oferecer condições de ser usado de maneira eficiente e confortável); Dimensão e espaço para aproximação e uso (Pode ser usado por todos com segurança, privacidade e conforto; elimina segregação.

A inclusão de parâmetros do Desenho Universal (DU) nas etapas de concepção projetual, de obra e comissionamento, contribui para a incorporação de novas atitudes profissionais em direção ao atendimento dos usuários com diferentes graus de habilidades e necessidades. Novas posturas no âmbito acadêmico, de ensino de projeto, e profissional, serão necessárias para aplicação de metodologias que envolvam maior criatividade projetiva e inclusão da participação do usuário no 


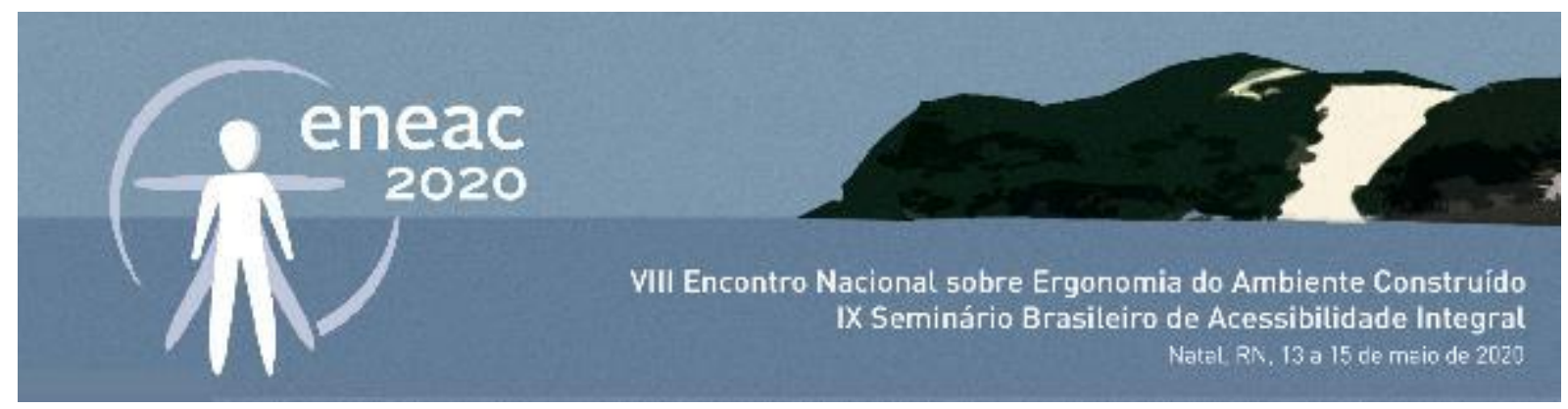

processo de projeto (BERNARDI, et al. 2011).

Pesquisas voltadas para análises de metodologias, problemas e soluções para pessoas com deficiência locomotora ou pessoas com mobilidade reduzida, são encontradas na literatura. Concorda-se com Machado e Lima (2015) que a possibilidade de deslocamento promove a inclusão social e possibilita o exercício de direitos das pessoas, principalmente as que se encontram em uma situação de mobilidade reduzida, temporária ou permanente. $O$ uso do método para a avaliação multicritério definido como Multicriteria Decision Analysis (MCDA) por Vougd, 1983; Carver, 1991; Malczewski,1999, possibilita o julgamento de valor, proporcionando uma opção que reconhece a subjetividade do problema e incorpora diversidades, buscando uma abordagem que considere a opinião desses usuários (MACHADO; LIMA, 2015).

Preiser (2003), por outro lado, utiliza a metodologia da Avaliação Pós-Ocupação como foco para o DU, também conhecida como knowledge-based design, com objetivo de melhorar a qualidade do projeto de serviços de saúde; na avalição pós-uso; e no desenvolvimento de banco de dados. A ênfase do processo de projeto está na estrutura de avaliação e desempenho de construção. O parâmetro de análise, baseado nos sete princípios do Desenho Universal, definidos por Ron Mace (Uso Equitativo, Flexibilidade de Uso, Uso intuitivo, Informação Perceptível, Tolerância ao Erro, Baixo Esforço, Tamanho e espaço para acesso) é utilizado como integrante do processo de humanização, criando uma atmosfera mais saudável e agradável para o usuário, podendo contribuir para sua reabilitação e até cura.

A Avaliação Pós-Ocupação (APO) permite avaliar o edifício em sua performance quanto maior e melhor sua usabilidade, sendo utilizada com foco nas lições aprendidas, tanto positivas quanto negativas, já que se acredita que o projeto deva ser baseado em um método detalhado para o programa, projeto e avaliação, mais que em características físicas (PREISER, 2003).

A APO, vista como um processo de retroalimentação de projetos e estratégia de pesquisa da Avaliação de Desempenho (ADU), deve considerar as questões de orientabilidade e navegabilidade Wayfinding Design, para avaliação do espaço construído. O propósito está em abastecer o processo de projeto para que resulte em espaços construídos mais acessíveis e eficientes quanto à orientabilidade (ABATE; KOWALTOWSKI; BERNARDI. 2014).

Diante da necessidade de conceber espaços capazes de proporcionar experiências espaciais agradáveis, seguras, acessíveis e que proporcionem autonomia de uso do espaço construído, este artigo apresenta uma pesquisa que tem como objetivo principal explorar as questões de acessibilidade locomotora no decorrer do processo de projeto em arquitetura. Nesse sentido, entende-se como necessário o conhecimento e a aplicação dos conceitos de wayfinding, para o qual, a elaboração de fluxogramas que expressem a dinâmica do espaço construído e sua intrínseca relação com as decisões de projeto são de fundamental importância para o processo arquitetônico em todas as suas fases.

Para o desenvolvimento desta pesquisa foi necessário aprofundar o conhecimento em temas que relacionem wayfinding e acessibilidade, e diagramas e fluxogramas, incluindo um breve estudo sobre iconografia, que serão aqui explanados.

\subsection{Wayfinding e Acessibilidade}




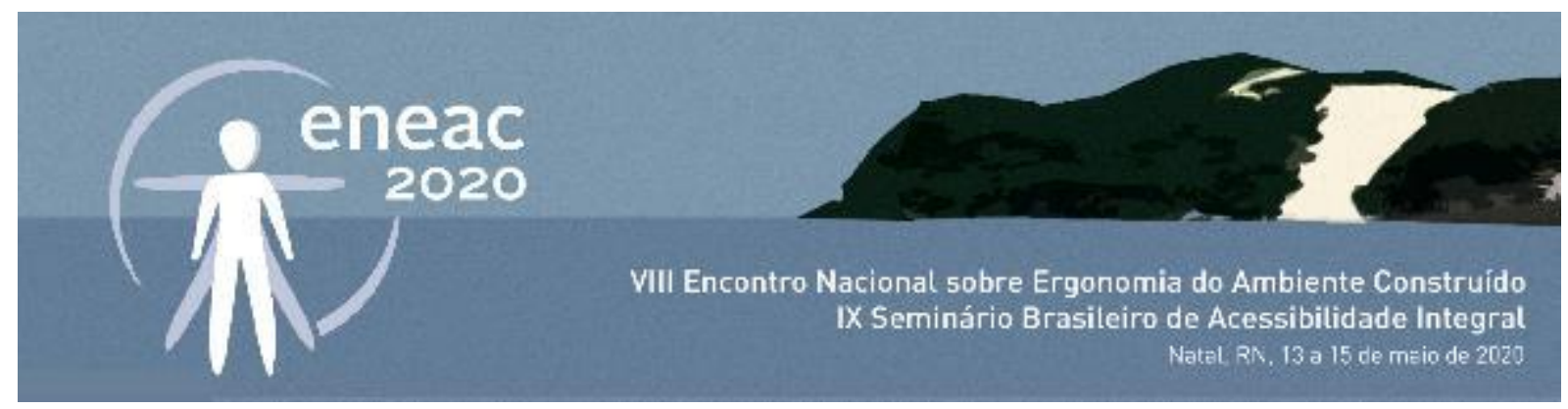

A maneira de chegar a um destino e situar-se no espaço se relaciona ao movimento orientado conhecido como wayfinding, e engloba processo de percepção, cognição e atuação comportamental (ARTHUR; PASSINI, 2002). A legibilidade de um espaço é facilitada e está associada a articulação espacial e a comunicação ambiental, visto que tais características contribuem para facilitar ou dificultar a localização de uma pessoa (BARBOSA; ORNSTEIN, 2014).

Em arquitetura, o planejamento das características do espaço e de sua organização espacial; a definição dos fluxos (horizontal e vertical); as características da circulação e seus elementos (escadas, rampas, elevadores, dentre outros); as referências/marcos, são itens que, associados a comunicação e wayfinding arquitetônico, são essenciais para definição e desenvolvimento de sistemas de orientação arquitetônica legíveis e eficientes quanto a circulação, acessibilidade e segurança (ALMEIDA; MARTINS, 2016). A informação e mobilidade são os fatores principais que permitem ao indivíduo participar de lugares e atividades, de forma autônoma (DISCHINGER, 2000).

As diretrizes para desenvolvimento de projetos com acessibilidade, mobilidade e percepção do espaço construído estão fundamentadas aos conceitos de legibilidade espacial (aprender um caminho e refazê-lo mentalmente) que está associada à facilidade do usuário de organizar a informação visual e inclui: identificação; agrupamento e ligação, e organização dos espaços com lógica arquitetônica e gráfica. A orientação espacial e legibilidade arquitetônica - wayfinding, estão associados aos espaços de conexão e distribuição, visto que a organização espacial é importante para o desenvolvimento do mapa mental ${ }^{1}$.

Além da legibilidade gráfica, composta por sistema de textos, pictogramas, fotografias, modelos e diagramas, os pontos nodais; bordas (limites); setores de ação e uso; as características espaciais do ambiente, como iluminação, cor/contraste, acústica, tamanhos/proporção, formas/volume, eixos/marcos arquitetônicos também são diretrizes para o projeto de wayfinding (BERNARDI, et al. 2011). Vale ressaltar que o Wayfinding é uma disciplina multidisciplinar que envolve arquitetura, design gráfico, paisagismo e a participação do patrocinador do projeto, compondo um sistema de orientabilidade para o indivíduo utilizar o projeto (arquitetônico e/ou urbano) em sua maior segurança e efetividade.

\subsection{Diagrama e Fluxograma}

A cultura contemporânea, fortemente vinculada aos fluxos, prioriza a transformação e os processos estabelecidos e modificados pelo tempo, (SOLA-MORALES, 2002, p. 127). Na arquitetura, a inclusão do tempo e do movimento tornam-se variáveis de projeto na busca por respostas formais e organizadoras do espaço. Segundo Fantinato (2017) desenvolveu-se, a partir da década de 1960, uma corrente arquitetônica metodológica com foco na análise e no processo de projeto. A materialização desta análise acontece de forma gráfica baseada em quadros comparativos e organogramas, reinterpretados em diagramas que expressam toda a complexidade dos projetos contemporâneos. Neste sentido, o diagrama e o fluxograma podem ser considerados como estratégia projetual e ferramenta gráfica associada ao fazer arquitetônico, a partir da materialização e organização de informações e do movimento. E também como um processo técnico, continuo que alimenta decisões espaciais, estabelece lógicas e organiza questões (NASCIMENTO, 2011).

O diagrama, considerado uma ferramenta de criação e representação das relações espaciais e formais, é uma linguagem que associa informações, suas relações e interação com o tempo e espaço. Aceita modificações, rompe com as práticas tradicionais da concepção projetual, como um processo 


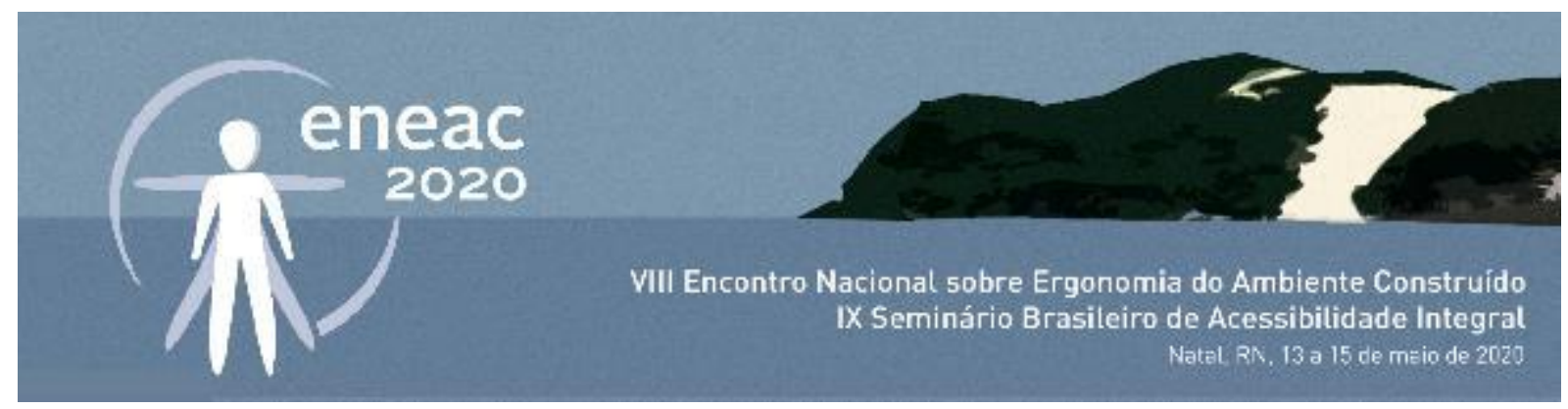

contínuo de geração de ideias e de apoio na fase de tomada de decisão (DUARTE, 1999). O diagrama substitui, por meio da modelagem, o processo bidimensional de criação, que é estático, pela investigação formal, dinâmica e efêmera (SPERLING, 1970), além de representar uma mudança na técnica e no processo de conhecimento arquitetônico a partir da segunda metade do século XX, com a vantagem de permitir a independência do objeto, visto que contém informações objetivas ou mensuráveis (SOMOL, 2007).

Ainda segundo Fantinato (2017) existe uma grande diversidade tipológica de diagramas.

Primeiramente eles estão classificados em três sistemas: de Projeção, de Composição e de Conteúdo. Na pesquisa apresentada neste artigo o que nos interessa é o Sistema de Conteúdo, quando o diagrama apresenta uma grande carga de teor informativo. Nesta categoria aparecem os diagramas de circulação, os programáticos e os sensoriais. Uma subclassificação apresenta os diagramas de Conteúdo Metodológico, que representam uma metodologia do processo de projeto, auxiliando nas estratégias de organização e otimização do projeto

A partir destes conceitos, entende-se que o diagrama pode ser aplicado como uma ferramenta metodológica ao procedimento de projeto e utilizado na fase de levantamento de dados - programa arquitetônico, na elaboração de estratégias projetuais e na apresentação do projeto (NASCIMENTO, 2011). O item Desenvolvimento da Pesquisa apresentará os diagramas de conteúdo de acessibilidade desenvolvidos e sua resultante no Fluxograma de Processo de Projeto, que será apresentado no item Resultados.

\section{OBJETIVO E METODOLOGIA}

Objetivou-se explorar questões de acessibilidade locomotora no decorrer do processo de projeto em arquitetura. Acredita-se que a acessibilidade para os usuários com diferentes graus de habilidades e necessidades é importante, e se observa que as deficiências locomotoras se destacam na literatura (cartilhas, artigos, projetos) e referências. Para este estudo, foi selecionada a tipologia de edifício cultural, pela diversidade de público e de atividades a serem oferecidas, pela necessidade de integração entre os diversos perfis de usuários, pela complexidade de fluxos (públicos x privativos) presentes nesta tipologia, pelo caráter público e abrangente que um edifício destinado à atividades culturais deve ter. Diante dos dados coletados, foi possível organizar um passo a passo em Fluxograma de Processo de Projeto, resultante de 3 diagramas metodológicos, que atua como guia para projetos arquitetônicos culturais, contribuindo para boas práticas acadêmicas e profissionais na inclusão da acessibilidade (VICTORIO, 2019).

Adotou-se procedimento de pesquisa exploratória qualitativa para o desenvolvimento deste trabalho. A metodologia consistiu na análise bibliográfica dos conceitos do Desenho Universal e acessibilidade , com foco na acessibilidade locomotora, aplicados em projetos arquitetônicos; interpretação préiconográfica de cartilhas (que auxiliou na composição gráfica do fluxograma), e de representação gráfica. Na sequência, tendo por base o referencial teórico, foram desenvolvidos diagramas para auxílio ao processo de projeto com ênfase na acessibilidade locomotora. 


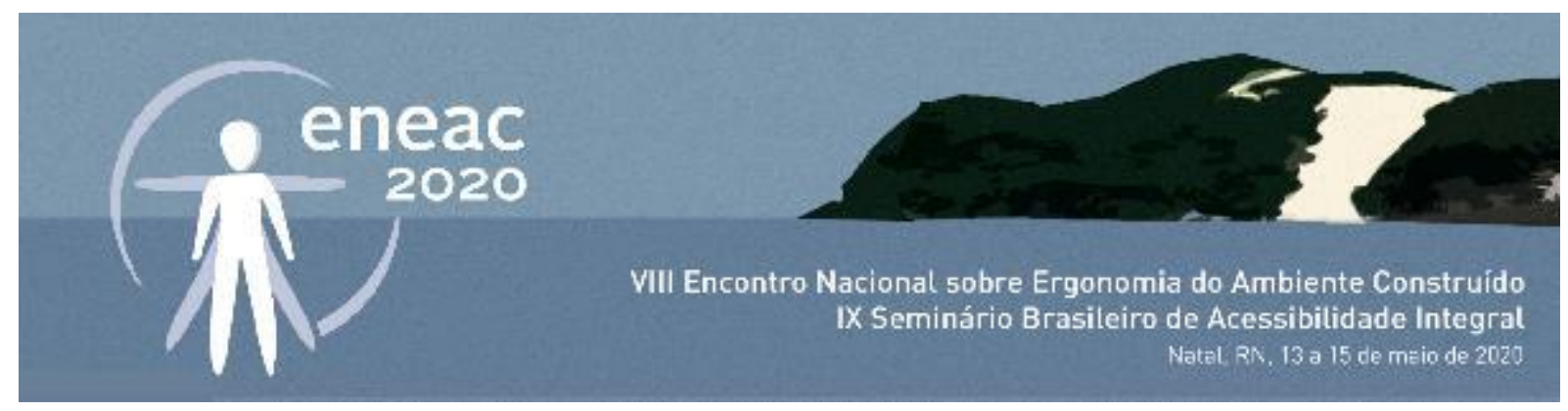

\section{DESENVOLVIMENTO DA PESQUISA}

Entende-se que no atual contexto de mudanças rápidas, é importante sentar-se à pesquisa e adotar uma estrutura sistemática sobre processos de projeto em arquitetura. Fatores que podem contribuir para decisões relacionadas as questões de acessibilidade locomotora nas etapas de concepção projetual. Soma-se, ainda conhecimento dos objetivos, dos fatos, dos conceitos e das necessidades de um projeto centrado na inclusão de parâmetros do Desenho Universal (DU) para uma solução arquitetônica de qualidade, com uso equitativo e flexível do espaço, e que devem acontecer nas primeiras fases do projeto, de forma interativa e cíclica.

A participação dos usuários nas diferentes fases do processo, para aquisição de informações de suporte as decisões de projeto; o envolvimento do cliente como membro da equipe de projeto; a comunicação efetiva entre cliente, usuário e projetista; e a análise compreensiva do problema, devem guiar os passos durante o projeto e estabelecer um conjunto sistemático de relações entre eles na procura de problemas, garantindo uma abordagem abrangente e fundamentada das decisões e soluções projetuais (PEÑA; PARSHALL, 2012).

Três diagramas de conteúdo foram desenvolvidos para considerar os itens necessários para um "Projeto Inclusivo" conforme o recorte de análise deste trabalho. Os diagramas buscam explorar questões de acessibilidade locomotora considerando o espaço público, semi-público e privado. Os itens normativos de wayfinding, foram adotados como conceitos do Desenho Universal, linguagem visual e sinalização, sustentabilidade social, segurança, e responsabilidades públicas e privadas.

A elaboração dos diagramas foi fundamentada na leitura sobre parâmetros pré-iconográficos. A compreensão dos métodos de análise iconográfica foi importante para este trabalho porque a iconografia é o estudo de representações e um diagrama de projeto arquitetônico trabalha com um tipo representação gráfica para expressar conceitos. Em arquitetura, conforme Laseu (2001), as etapas do processo de projeto são normalmente registradas com algum tipo de modelo gráfico (diagramas, croquis etc.), e a linguagem gráfica bem definida é importante para o pensamento do projeto. As ferramentas de representação gráfica fazem parte do processo criativo e influenciam no pensamento e na resolução criativa de problemas.

Um breve conhecimento sobre iconografia e métodos de análise iconográfica foi necessário para esta leitura. Segundo Panofsky (2009), uma análise iconográfica é um método que coleta e classifica uma imagem, mas não se considera obrigada ou capacitada a investigar a gênese desta imagem. Fazem parte deste processo a descrição pré-iconográfica, a descrição iconográfica e a descrição iconológica.

A descrição pré-iconográfica está relacionada ao significado primário que consiste em identificar formas, linhas, cores, volumes, objetos, presentes nas imagens. Foi realizada uma categorização das imagens das cartilhas de acordo com o Filtro Conceitual de Sassaki (1997) (que classifica a acessibilidade em : arquitetônica, comunicacional, metodológica, programática, atitudinal, discriminatória); categorização pelas deficiências (visual, auditiva, intelectual, física, múltipla, mobilidade reduzida) e pela legislação nacional de acessibilidade. Realizar uma análise préiconográfica é uma forma de se obter informações para a documentação, etapa conhecida como indexação. A indexação (coleta de referências e dados sobre o tema) permitiu a identificação do uso 


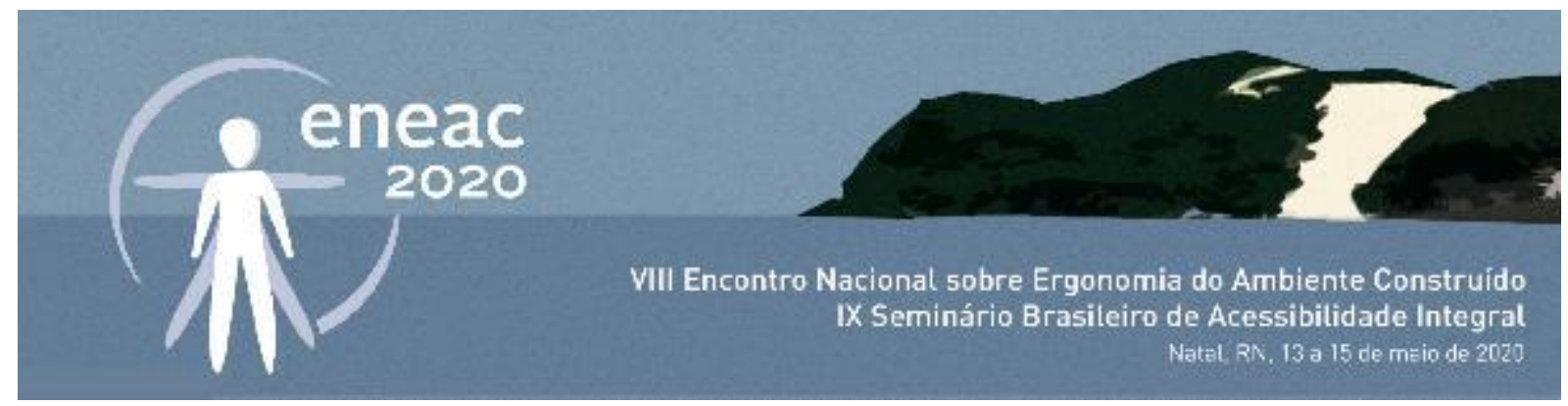

de imagens desenvolvidas com intuito de ilustrar o conteúdo escrito.

A descrição iconográfica está relacionada ao significado secundário e consiste na ligação das composições das imagens com assuntos e conceitos advindos da percepção das convenções sociais e culturais. E a descrição iconológica está relacionada ao significado que advém de fatores históricos e sociais.

Nesta pesquisa foi realizada a análise pré-iconográfica de 02 (duas) cartilhas de orientação para acessibilidade, desenvolvidas no âmbito nacional por prefeituras e/ou Conselhos Regionais de Arquitetura e Urbanismo ou de Engenharia Civil, distribuídas de forma gratuita via rede internet. As cartilhas foram pré-selecionadas da pesquisa de Geia (2018), que apresenta uma análise iconográfica de cartilhas desenvolvidas no período de 2015 à 2019, compreendendo portanto o período após a revisão da NBR9050/2015.

\subsection{Desenvolvimento dos Diagramas de Conteúdo Metodológico}

Inicialmente, para a etapa de levantamento de questões que devem ser discutidas no processo de projeto para edifícios públicos culturais, foram estabelecidas escalas de aproximação: espaço público (Figura 1), semi-público (Figura 2) e privado (Figura 3). Nestas escalas foram colocadas questões primordiais para um Projeto Inclusivo, como de acessibilidade e Desenho Universal e demais fatores que orbitam em torno destes conceitos. Foram desenvolvidos 03 (três) diagramas de conteúdo metodológico com a temática da acessibilidade.

Figura 1: Diagrama Metodológico 1: Acessibilidade no âmbito público.

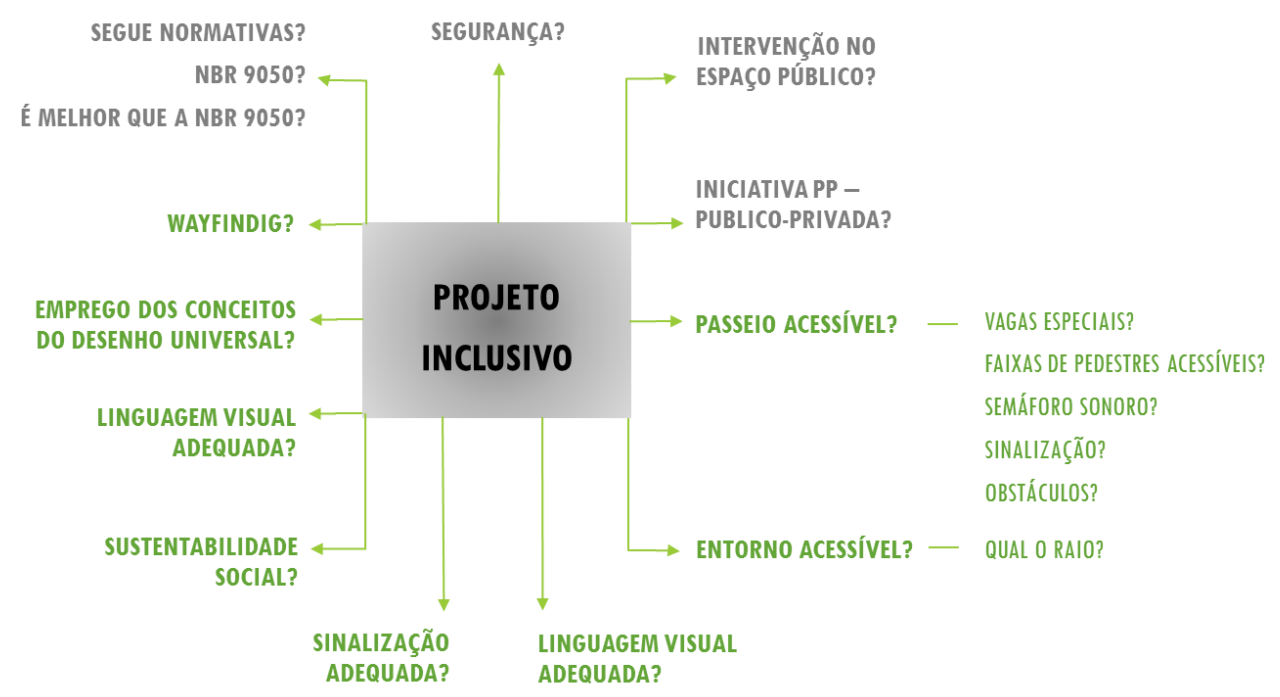

Fonte: autores, 2019. 


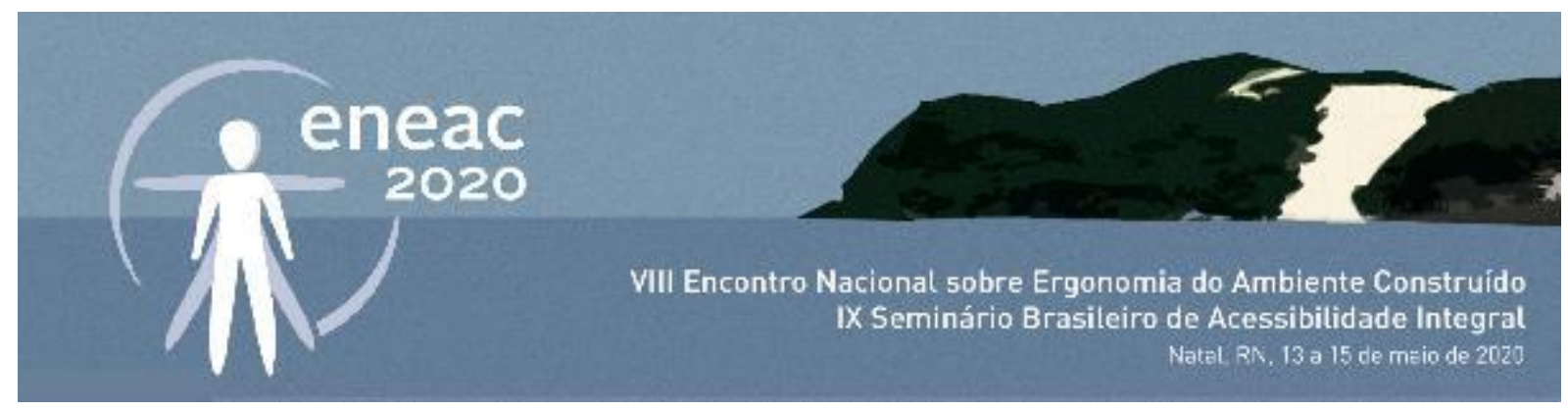

A acessibilidade no espaço público sempre é um ponto com várias vertentes e problemáticas a serem solucionadas, como exemplifica o Diagrama Metodológico 1 (Figura 1). Quem tomará conta daquele espaço acessível? Os órgãos públicos se responsabilizarão pela adequação e pela manutenção de tais espaços. Dessa forma, deve-se atentar para uma série de fatores que fazem com que o projeto em âmbito privado tenha um percurso e uma forma de chegada acessível a partir do âmbito público. Em muitos casos, o trajeto que será percorrido, possivelmente a transição entre um ponto de parada do transporte público até o edifício, não apresenta adaptação adequada para o pleno caminhar de um deficiente ou uma pessoa com mobilidade reduzida.

Apesar dos projetos públicos estarem mais voltados para a deficiência locomotora, um passeio adequado faz total diferença para todos e a falta dele, pode causar acidentes. Itens como vagas especiais, faixas de pedestres em pontos estratégicos, semáforos sonoros, sinalização adequada e a ausência de obstáculos são alguns elementos que podem ser colocados como primordiais para a boa mobilidade pública, como demonstrado por Machado e Lima (2015) ao realizarem uma pesquisa utilizando metodologia de Avaliação Multicritério da acessibilidade de pessoas com mobilidade. Além de todos esses pontos, outras perguntas podem ser colocadas: qual o raio de atuação dessa adequação? Toda a área aplica os conceitos do Desenho Universal? O wayfinding é óbvio? O projeto público está de acordo com a NBR 9050? É melhor do que a NBR? O âmbito semi-público também traz algumas dessas preocupações, conforme pode ser destacado pelo Diagrama Metodológico 2 (Figura 2).

Figura 2: Diagrama Metodológico 2 : Acessibilidade no âmbito semi-público.

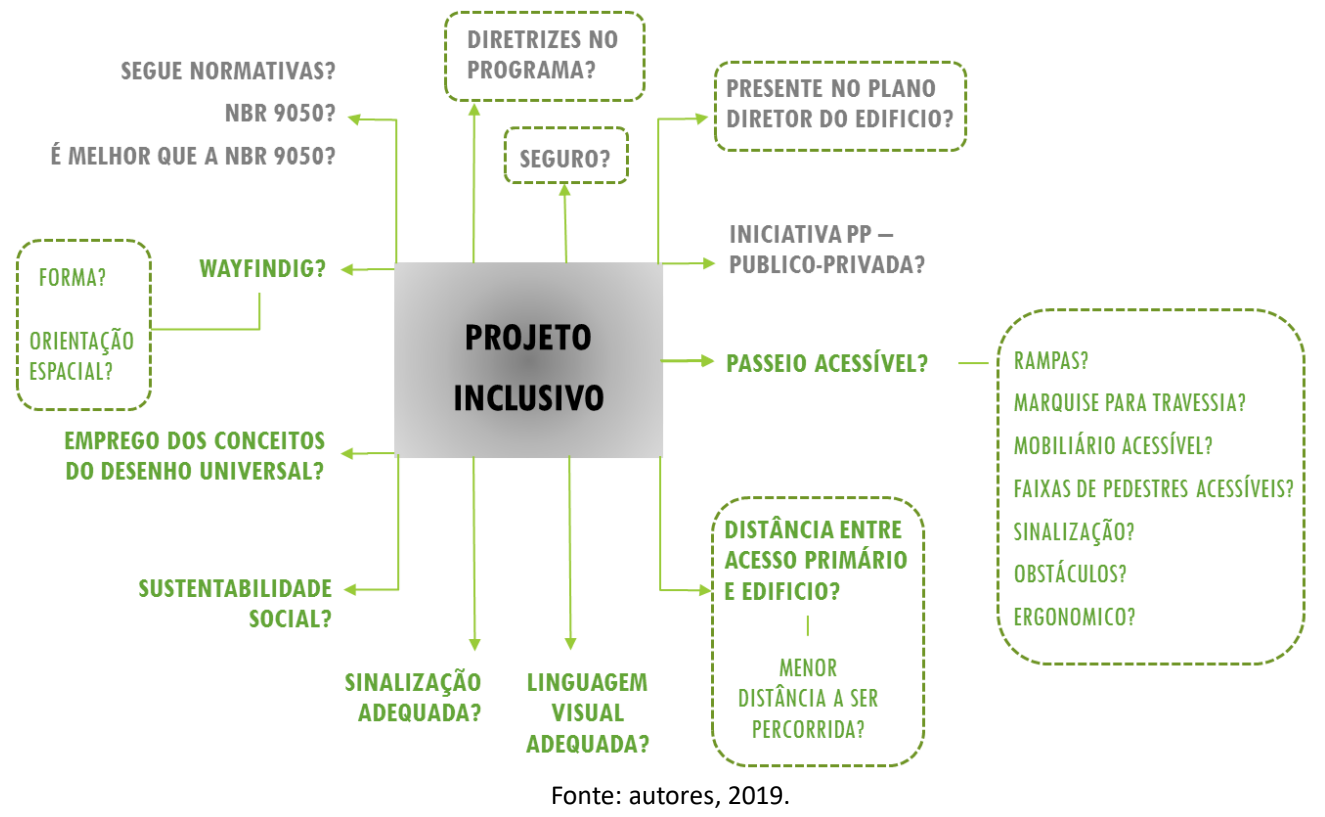

Quando chegamos ao âmbito semi-público, aquele onde acontece a transição entre o espaço público e o privado; cria-se sempre um impasse quanto a administração e manutenção de tal área. Quem zela e preza por ela, o poder público, ou a iniciativa privada? Apesar de ser um ambiente de acesso ao edifício e de total interesse privado, mantém-se um espaço público. Além de tudo, é onde o 


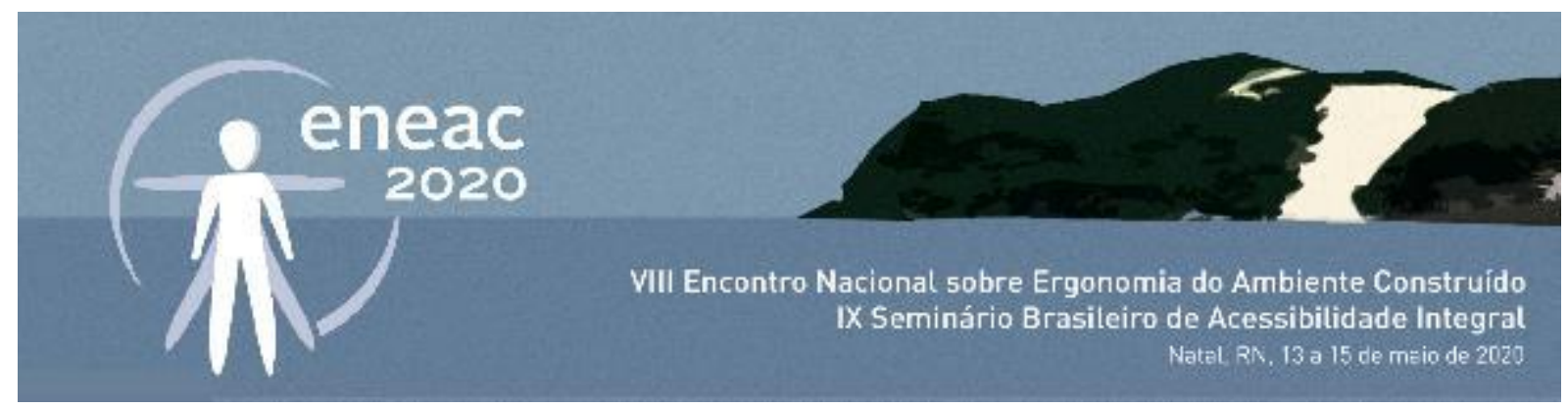

wayfinding aplica-se com maior caracterização, visto que o projeto deve identificar-se por si só; apesar da necessidade da sinalização adequada e correta linguagem visual aplicada. O passeio, novamente torna-se um dos pontos de maior destaque e necessidade de adaptações, assim como no espaço público. Há rampas, com inclinações adequadas? O mobiliário existente é acessível? A faixa de pedestre está sinalizada e no local correto? O espaço como um todo propõe uma curta distância entre o âmbito público e o privado? Mostra-se com os conceitos do Desenho Universal? Segue ou supera as exigências da NBR 9050?

Pode-se citar como exemplo a série de Avaliações Pós-Ocupação - APO em hospitais norteamericanos realizada por Preiser (2003), utilizando os preceitos do Desenho Universal como parte integrante do método de avaliação. Em um dos casos, a distância entre o estacionamento e a recepção principal era tão longa, que muitas vezes gerava chamadas de emergência para pacientes com problemas cardíacos, além de toda a carga de estresse atribuída. Os resultados trazem informações preciosas não somente para reformas e adaptações do edifício hospitalar, que está em constante transformação, mas também para outras tipologias de projeto, auxiliando a refletir sobre a dinâmica de fluxos decorrentes das necessidades espaciais e pessoais.

Ao nos depararmos no espaço privado, o Diagrama Metodológico 3 representado pela Figura 3, mostra alguns cuidados diferentes em relação aos anteriores. A circulação se mantém como um dos principais e mais críticos pontos; devendo estar bem sinalizada, sem a presença de obstáculos e na movimentação entre pavimentos, os elevadores ou rampas precisam sempre mostrar-se como uma solução integrante do projeto, e não um ponto de solução técnica necessária.

Figura 3: Diagrama Metodológico 3 : Acessibilidade no âmbito privado.

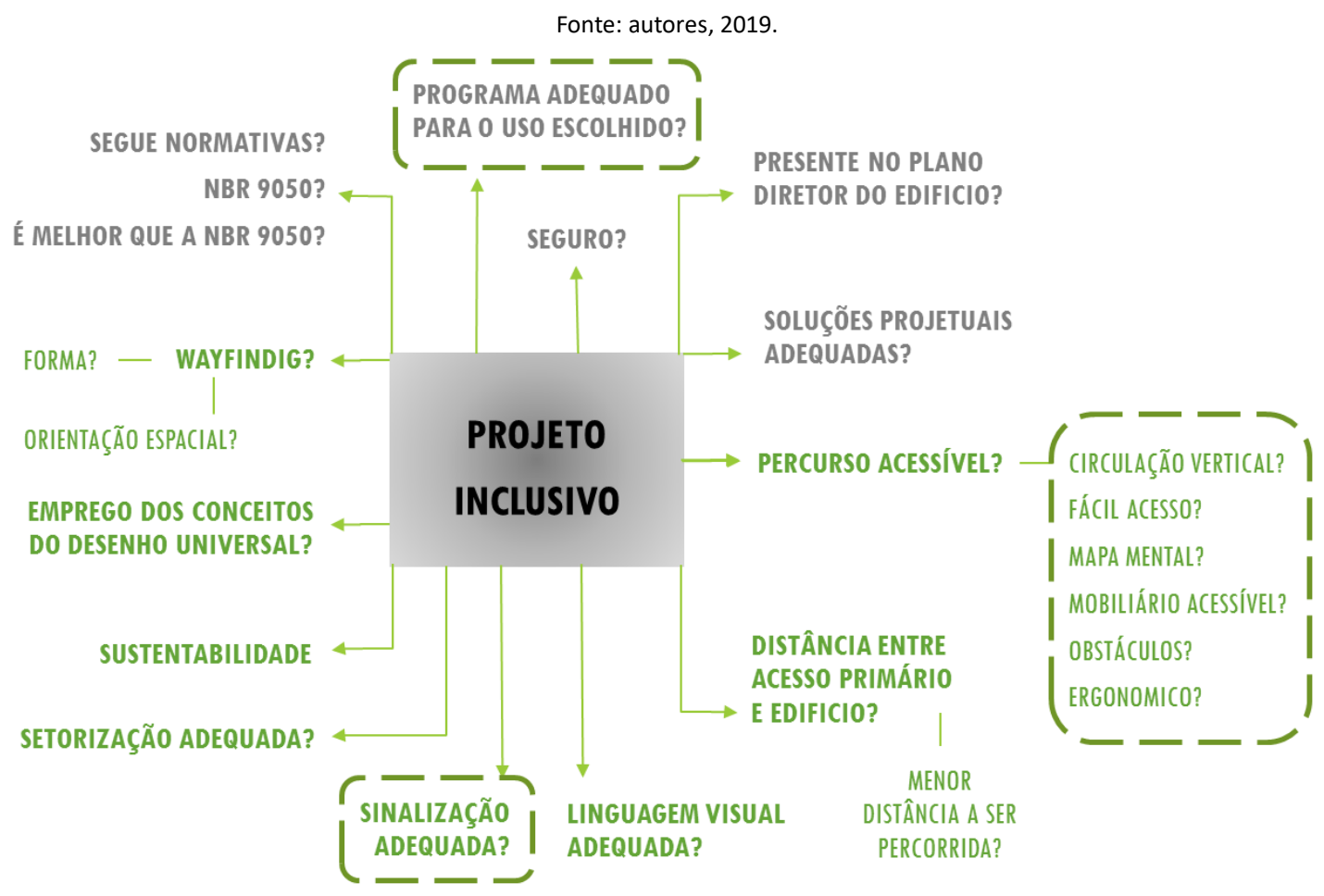




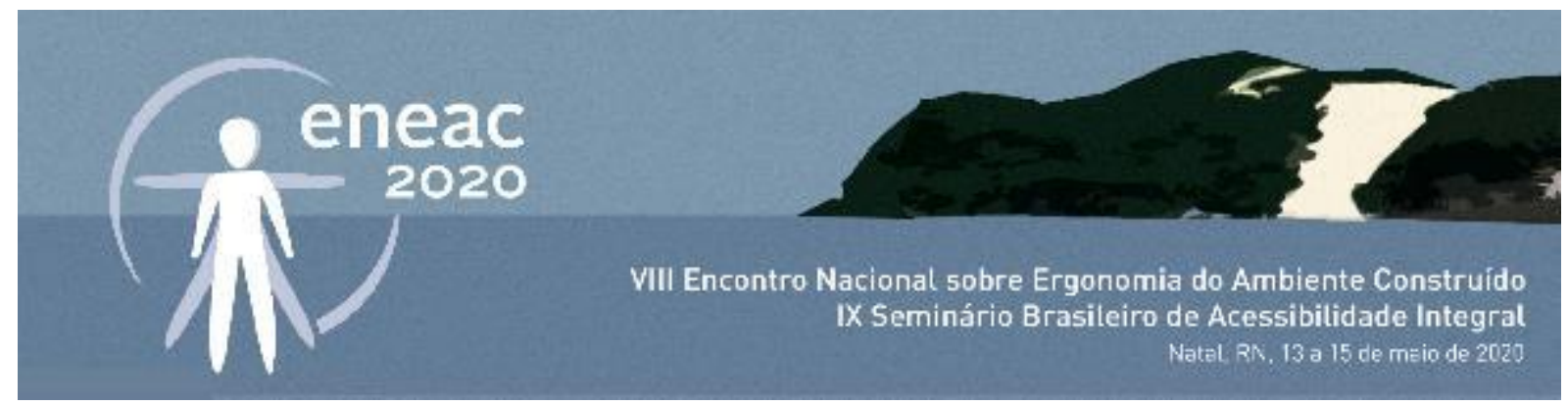

Os conceitos do Desenho Universal devem estar presentes desde os primeiros croquis do projeto, bem como uma boa organização setorial que resulta na adequada circulação. Quando se fala de setorização e organização dos fluxos de circulação, Bross (2013) diz que ao realizar-se uma APO, devese primeiro identificar a setorização do edifício para depois, apontar suas principais circulações. Essa abordagem pode ser adaptada e aplicada no início do desenvolvimento do projeto, definindo a melhor setorização em um plano de massas e depois identificando as principais circulações, à fim de fundamentar a etapa inicial de projeto.

O plano diretor do edifício também deve prever alterações e adequações ao longo do tempo, de preferência como resultado de uma Avaliação Pós-Ocupação realizada junto à um grupo focal. A NBR 9050, novamente precisa ser levada em consideração e utilizada em todas as etapas do projeto. Mas não como um guia, e sim como um ponto de partida. De maneira geral, o que está na norma se configura como o mínimo, não sendo necessariamente o mais completo para a melhor experiência do usuário, o que pode continuar causando dificuldades.

\section{RESULTADOS}

\subsection{Fluxograma Final}

A partir do levantamento anterior desenvolveu-se um fluxograma "roteiro" , fundamentado nas etapas expostas pela ABNT NBR 16636-2 ${ }^{2}$, como resultado da estruturação das etapas do processo de projeto para edifícios públicos, com destaque para os conceitos do Desenho Universal, em especial a acessibilidade locomotora. A participação de um Grupo Focal - um grupo de possíveis usuários do edifício, onde incluem-se pessoas com deficiências ou não, com mobilidade reduzida ou não e outros com expertise no assunto será colocado em pauta, objetivando sempre um debate saudável a ponto de agregar conhecimento, vivências e diferentes experiências que possam contribuir ativamente para o melhor desenvolvimento do projeto e nova fundamentação de seu processo, de acordo com as necessidades expostas. (Figura 4)

Propõe-se então um fluxograma de procedimento de projeto, que tem como premissas os conceitos já expostos na NBR 16636-2, onde as fases de desenvolvimento do projeto arquitetônico, elencados nos diagramas anteriores, são sub-setorizadas, a ponto de facilitar a compreensão final. 


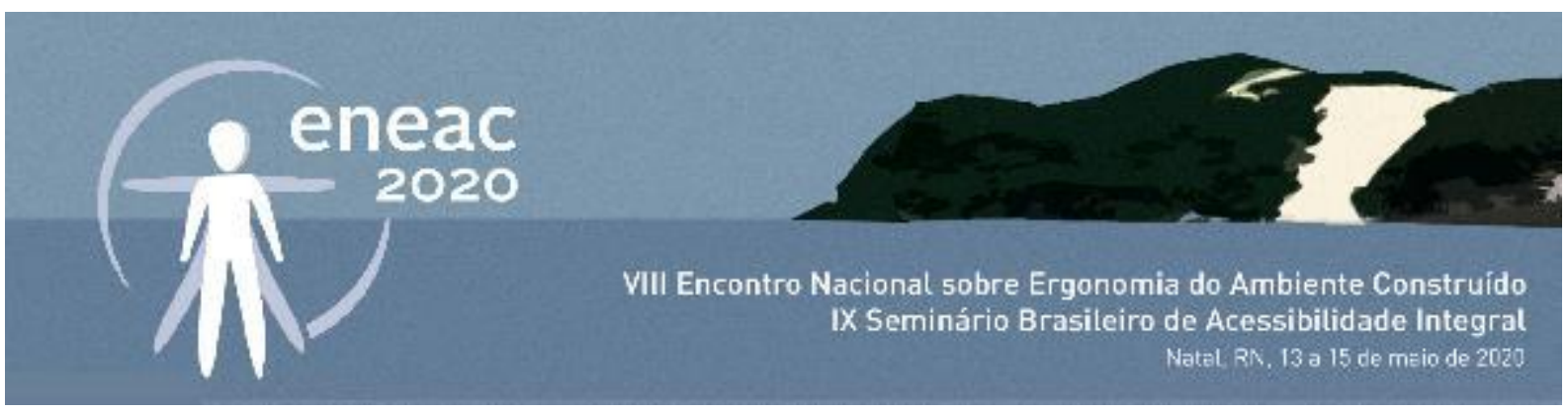

Figura 4: Fluxograma de processo de projeto

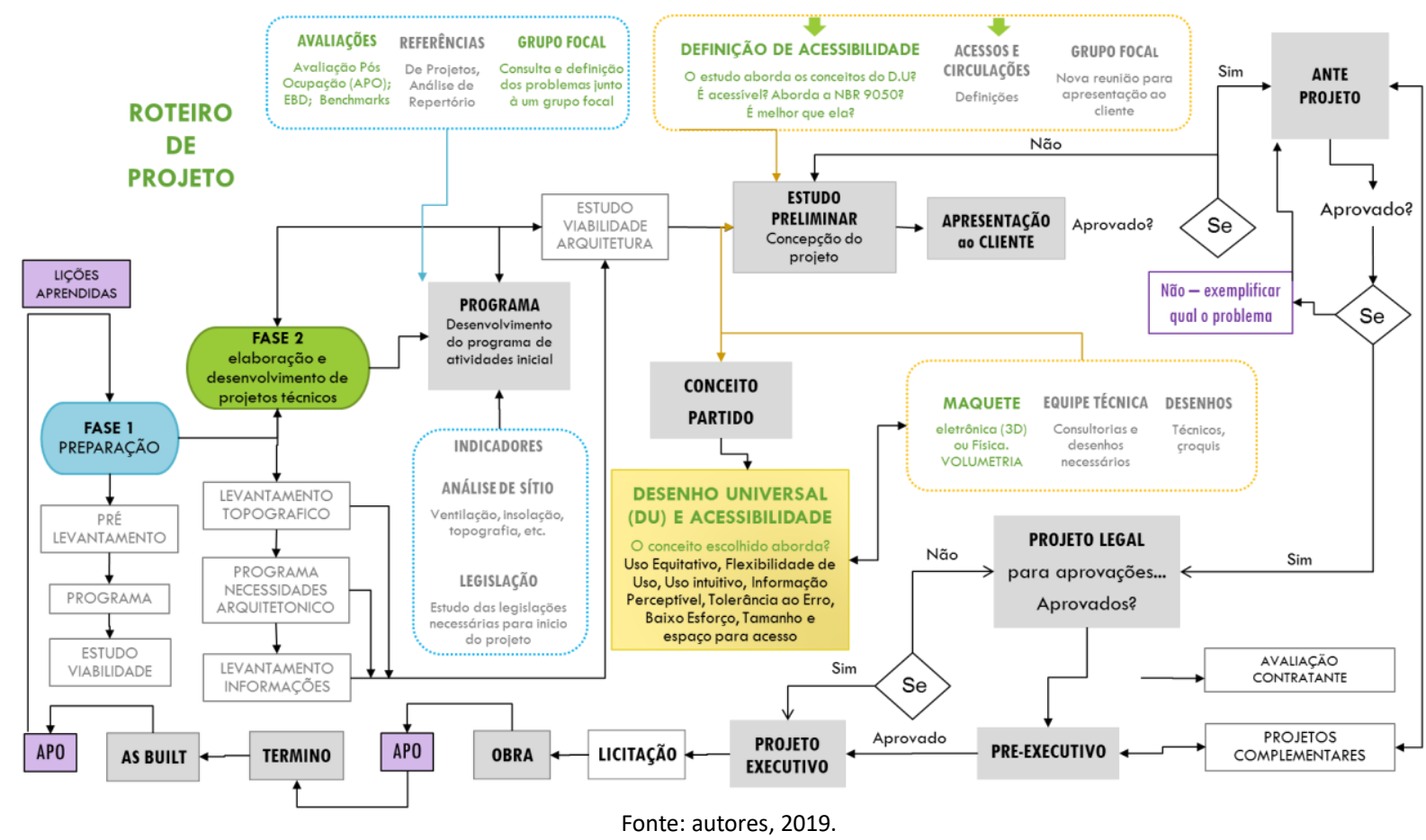

\subsubsection{Fase 1}

No que foi identificado como Fase 1, apresentam-se as atividades preparatórias para o pleno desenvolvimento de um projeto final, incluindo um pré-levantamento, elaboração de um programa de necessidades primário e também, um completo estudo de viabilidade.

\subsubsection{Fase 2}

Na Fase 2, Elaboração e Desenvolvimento de Projetos Técnicos, concentram-se atividades essenciais para o pleno desenvolvimento de um projeto arquitetônico, como um levantamento topográfico, um refinamento do programa de necessidades primário e completo levantamento socioeconômico; a fim de nutrir o projetista com informações variadas e necessárias para a elaboração adequada do projeto. Tais etapas, podem levar a necessidade do desenvolvimento de um novo estudo de viabilidade arquitetônico ou então, após uma nova atualização do programa com estudos e informações mais complexas, como estudos de caso, APO's, nova análise de sítio, estudo prévio de legislações locais e outra consulta com o grupo focal para discussões e adequações. A partir daí, inicia-se o desenvolvimento dos estudos preliminares de projeto.

\subsection{2.a Estudo Preliminar}

O Estudo Preliminar pode ser considerado uma das etapas com maior acúmulo de atividades, onde serão elaborados estudos de projeto, visando sempre a inclusão de etapas que o caracterize como 


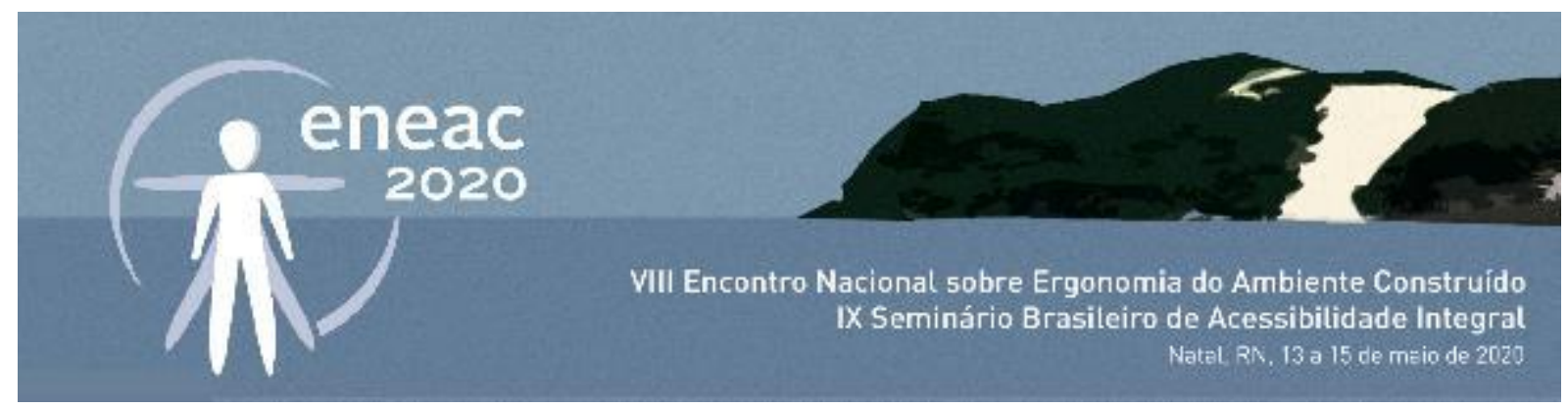

"Projeto Inclusivo". Nesta etapa, os croquis tomam forma a partir do partido definido e devem abordar os conceitos do D.U desde seu início. A partir dessa definição conceitual e possivelmente formal, o estudo das circulações deve ser elaborado pelo arquiteto responsável para então, com um desenvolvimento de maquetes (eletrônicas ou físicas), desenhos técnicos prévios e croquis esquemáticos, realizar-se uma nova reunião com o Grupo Focal para levantamento das soluções abordadas, e busca de soluções nos problemas existentes. Após a aprovação do projeto em um consenso, uma reunião de apresentação do projeto ao cliente deve ser agendada.

\subsection{2.b Apresentação ao Cliente}

Com um material mais maduro e elaborado, a apresentação para o cliente define a fase inicial de aprovações e readequações, que já pode ter sido iniciada com o Grupo Focal. Caso sejam solicitadas alterações, dependendo de quão comprometedoras ao conceito e projeto apresentado, o desenvolvimento retorna a uma fase do Estudo Preliminar para readequação.

\subsection{2.c Projeto}

Após as aprovações do cliente, chega-se a etapa do Ante-projeto que, caso não seja aprovado pode, novamente, levar o processo de volta ao Estudo Preliminar. Quando aprovado, desenvolvem-se os projetos legais para aprovação junto a órgãos legisladores e liberação do mesmo para desenvolvimento dos projetos complementares.

Se aprovados, os Projetos Pré-executivos e complementares são desenvolvidos onde, novamente, podem passar por uma avaliação e discussão junto ao Grupo Focal, para verificação das soluções aplicadas. A compatibilização destes projetos deve ser realizada pela equipe de arquitetura e a cada "se", o problema deve ser exemplificado para servir de lições aprendidas. A partir daí, desenvolvemse os Projetos Executivos e etapas burocráticas (como licitações) para então, o início da obra.

\subsection{2.d Obra}

Durante o processo de obra, o profissional responsável pelo acompanhamento das execuções deve se atentar para mínimos detalhes que fazem total diferença para locomoção. Antes do início do processo, o ideal é que se realize uma conversa com a equipe que realizará a execução e explique como pequenos desníveis, por exemplo, podem comprometer a movimentação de uma pessoa com mobilidade reduzida e até causar acidentes.

Antes da inauguração do espaço e abertura ao público, uma avaliação pré-ocupação pode ser desenvolvida com o Grupo Focal a fim de verificar pontos positivos e negativos; podendo ocasionar em alterações antes da finalização do processo. Após a real inauguração, uma avaliação pós ocupação pode ser desenvolvida onde seus pontos de alteração podem ser incluídos no plano diretor do edifício, a ponto de sempre estar realizando reformas e reestruturações para a constante melhoria e adaptação do local as mais diferentes necessidades. 


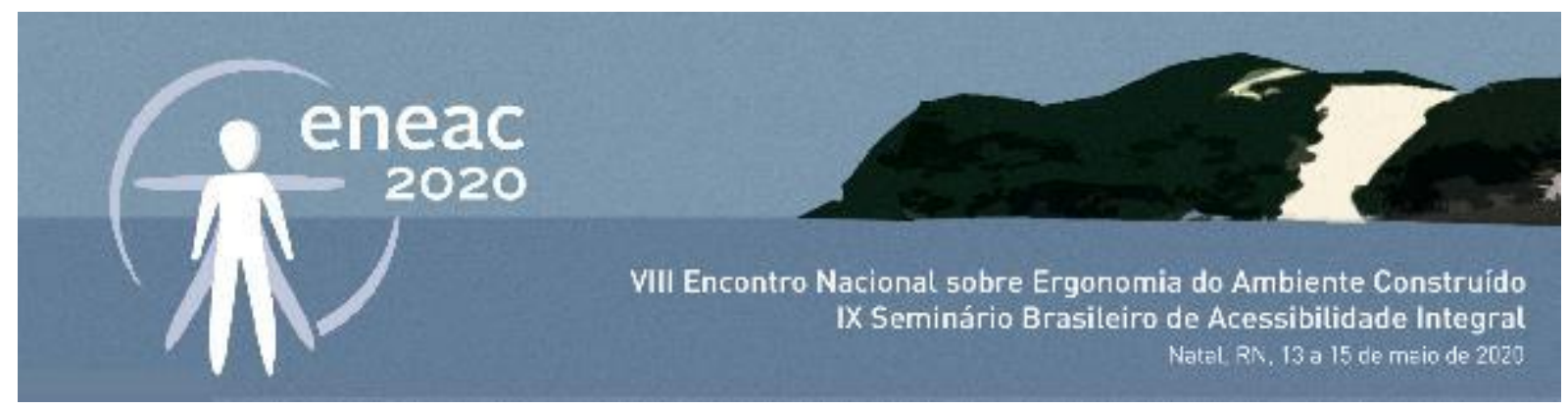

\section{CONSIDERAÇÕES FINAIS}

Questões do Desenho Universal e Acessibilidade devem ser abrigadas e utilizadas em qualquer projeto, seja ele público, semi-privado ou privado. Hoje, existe uma grande quantidade de cartilhas e material técnico que abordam as deficiências locomotoras e mobilidade reduzida, além das normas regulamentadoras, a exemplo da própria NBR 9050/2015. Assim sendo, tomando como base esse banco de informações e trabalhando com a indexação em análises pré-iconográficas das cartilhas, leituras e referenciais teóricos de materiais pertinentes, como as normativas apresentadas, 0 desenvolvimento dos diagramas e fluxogramas visa uma organização e facilitação das informações necessárias no desenvolvimento de qualquer projeto, seja ele arquitetônico ou urbano.

Um fluxograma bem elaborado auxilia também na visualização clara das etapas do processo, permitindo atentar-se para as fases onde as definições e decisões são de extrema importância, podendo comprometer todas as etapas futuras. Este fluxograma de projeto aqui apresentado colocou como protagonista o conceito do Desenho Universal e a participação intrínseca dos usuários (na figura do Grupo Focal) não apenas nas etapas preliminares, mas em outros momentos do processo, como consultores das decisões propostas pelo corpo técnico de projeto, com um foco no emprego de quesitos, conceitos e mecanismos de desenvolvimento, gestão e projeto, que fazem com que o resultado final seja expresso em um Projeto Inclusivo.

Embora os diagramas e fluxograma apresentados nesta pesquisa tenham sido orientados para edifícios de uso público, com atividades voltada à cultura, eles podem ser detalhados de forma mais específica para diferentes atividades, como apoio ao processo de projeto. A linguagem gráfica dos diagramas é um recurso para o pensar em arquitetura e sua comunicação, e faz parte do processo criativo. Desta maneira, os resultados apresentados neste trabalho, demostraram-se eficientes para a compreensão do problema e organização das informações relevantes ao processo de projeto, e podem contribuir para metodologia de projeto com foco na acessibilidade integral.

\section{REFERÊNCIAS}

ABATE, T.P.; KOWALTOWSKI, D.C.C.K.; BERNARDI, N.; Avaliação Pós-Ocupação (APO) e o Wayfinding Design. In: XV Encontro Nacional de Tecnologia do Ambiente Construído - ENTAC, 2014. Maceió, Alagoas.

ABNT - ASSOCIAÇÃO BRASILEIRA DE NORMAS TÉCNICAS. NBR 9050: Acessibilidade e edificações, mobiliário, espaços e equipamentos urbanos. Rio de Janeiro: S,2015.

ABNT - ASSOCIAÇÃO BRASILEIRA DE NORMAS TÉCNICAS. NBR 16.636-1: Diretrizes e Terminologia; NBR 16.636-2: Projeto Arquitetônico. ABNT, jun. 2017

ALMEIDA, M. F. X. M.; MARTINS, B.M.; O conceito de wayfinding na concepção de projetos arquitetonicos: interdisciplinaridade a serviço da inclusão. Revista de Arquitetura e Urbanismo Architecton, 2016.

ARTHUR, P.; PASSINI, R. Wayfinding: people, signs and architecture. Ontario: McGraw-Hill Ryerson Ltd, 1992. Reissued as a collector's edition in 2002 by Focus Strategic Communications, Inc.

BARBOSA, M. B.; ORNSTEIN, S. W. Wayfinding e acessibilidade para pessoas com deficiência visual em sistemas metroferroviários. In:III Encontro da Associação Nacional de Pesquisa e Pós-graduação em Arquitetura e Urbanismo - III ENANPARQ, 2014. São Paulo. 


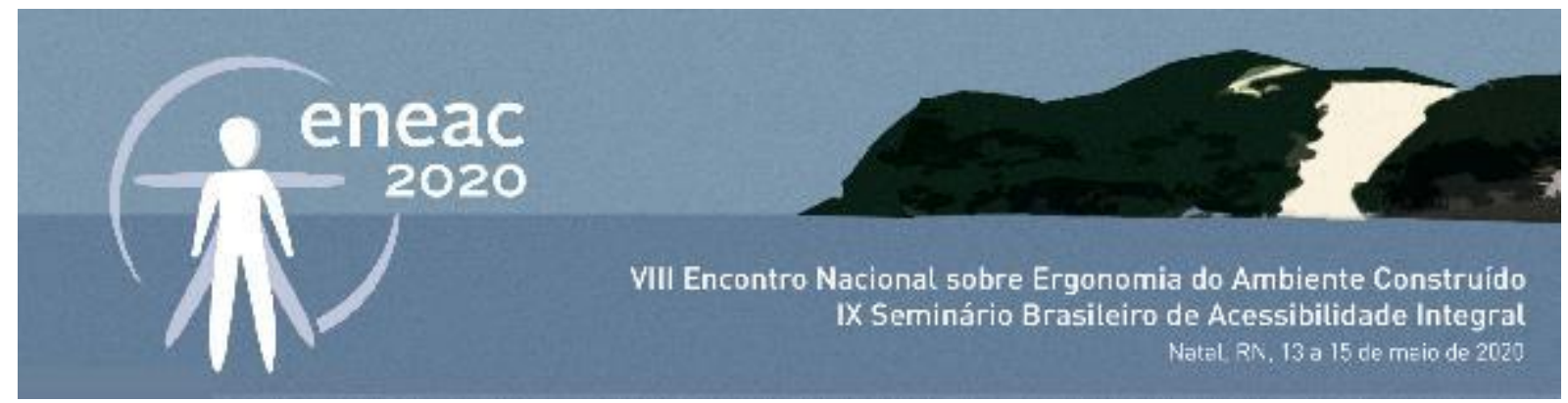

BERNARDI, N. et al. O desenho universal no processo de projeto. In: KOWALTOWSKI, D. C. C. K. (org.). O processo de projeto em arquitetura: da teoria à tecnologia. São Paulo: Oficina de Textos, 2011, pp. 222-244.

BROSS, J. C. (2013 /no prelo/). Compreendendo o Edifício de Saúde. São Paulo: Editora Atheneu.

CARVER, S. J. Integrating multi-criteria evaluation with geographical information systems. Internacional Journal of Geographic Information Systems, v.5, n.3, 1991, pp.321-339.

DISCHINGER, M. Designing for all senses: accessible spaces for visually impaired citizens, Goteborg, Chalmers University of Technology, 2000.

DUARTE, F. Arquitetura e tecnologias de informação: da revolução industrial à revolução digital. Campinas: Editora Unicamp, 1999.

FANTINATO, D. M. O uso de diagramas na representação de projetos em publicações de arquitetura: o caso da Domus. Dissertação (Mestrado). Orient. Prof. Dr. Daniel de Carvalho Moreiro. Programa de Pós-graduação em Arquitetura, Tecnologia e Cidade. Faculdade de Engenharia Civil, Arquitetura e Urbanismo, Universidade Estadual de Campinas, 2017.

GEIA, M. L.; BERNARDI, n. Análise Iconográfica sobre acessibilidade, ergonomia e inclusão em Cartilhas de Acessibilidade Urbana. In: Anais do 9o. Seminário Internacional sobre Ensino, Pesquisa e Prática em Projeto de Arquitetura e Urbanismo- Projetar: Arquitetura e Cidade: privilégios, conflitos e possibilidades.Volume 1. Curitiba: UFPR: Universidade Positivo, 2019.

LASEAU, P. Graphic Thinking for Architects and Designer. New jersey: John Wiley \& Sons, 2001.

MACE, R.; Hardie, G. Place, J. Accessible Environments Toward Universal Design. New York, USA: North Carolina State University, 1991.

MACHADO, M. H.; LIMA, J. P. Avaliação multicritério da acessibilidade de pessoas com mobilidade reduzida: um estudo na região central de Itajubá (MG). URBE, Revista Brasileira de Gestão Urbana [online]. v. 7, n. 3, 2015, pp.368-382.

MALCZEWSKI, J. GIS and multicriteria decision analysis. New York: John Wiley \& Sons, 1999.

NASCIMENTO, D. M. Arquitetura como procedimento e o diagrama como seu instrumento de projeto. V Seminário Nacional sobre Ensino e Pesquisa em Projeto de Arquitetura - PROJETAR 2011 - Belo Horizonte/MG. Disponivel em www.projedata.grupoprojetar.ufrn.br

PEÑA, W.M.;PARSHALL, S.A. Problem Seeking. 4. ed. New York: John Wiley \& Sons, 2012.

PANOFSKY, Erwin. Significado nas artes visuais. Ed. Perspectiva S.A, São Paulo, SP, 2009.

PREISER, W. F. E. International Academy for Design and Health, 2003. Disponível em < https://www.brikbase.org/sites/default/files/38WG-Preiser-WCDH-2003.pdf> Acesso em: 19 mar. 2019.

SASSAKI, Romeu Kazumi. Inclusão: Construindo uma Sociedade para todos. Rio de Janeiro, WVA, 1997.

SOMOL, R. E. Texto sonso, ou a base diagramática da arquitetura contemporânea. RISCO, pp. 179-191, 2007.

SOLA-MORALES, I. de. Territorios. Barcelona: Editoriao Gustavo Gili, 2002.

SPERLING, D. Diagramas e eventos: o espaço e a forma em mutação. Anais. XII Congresso da Sociedade Iberoamericana de Gráfica Digital. Universidade de São Paulo (USP), São Paulo, 2008.

VICTORIO, E. R. As questões da circulação em arquitetura com base na análise de soluções de projetos contemporâneos. Dissertação (Mestrado em Arquitetura, Tecnologia e Cidade) - Universidade Estadual de Campinas (UNICAMP), Campinas, 2019.

VOOGD, H. Multicriteria evaluation for urban and regional planning. London: Pion, 1983. 


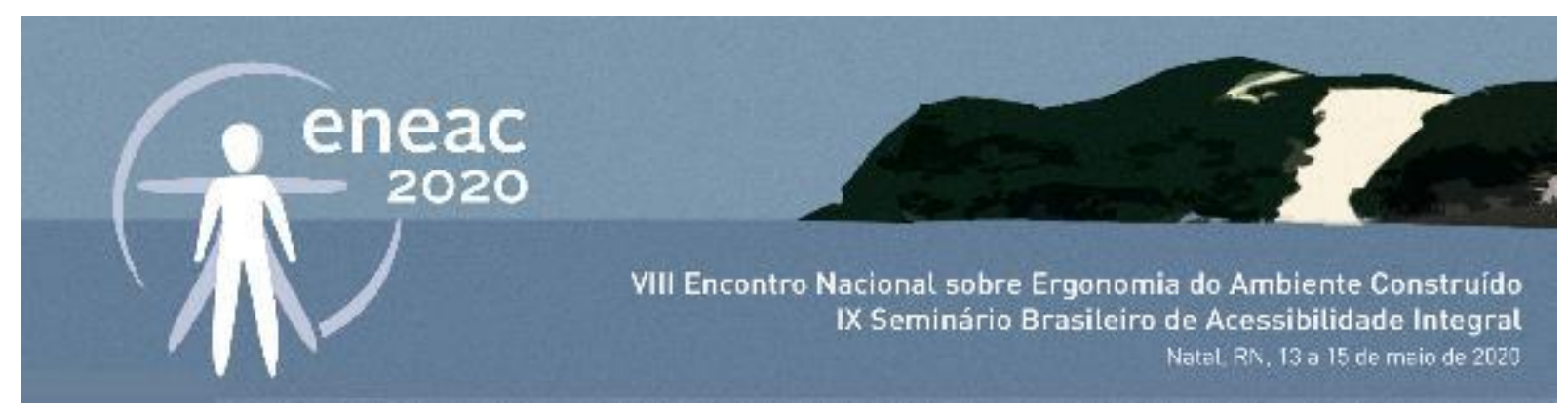

NOTAS

1 Os mapas mentais - são modelos cognitivos e modelos mentais são tipos de processamento mental, que procuram representar, com o máximo de detalhes possíveis, o relacionamento conceitual existente entre informações que normalmente estão fragmentadas, difusas e pulverizadas no ambiente operacional ou corporativo. Um mapa cognitivo é um mapa mental aprendido de um ambiente espacial, geralmente sem estar consciente do fato de que você tenha aprendido. Disponível em < https://pt.wikipedia.org/wiki/Mapa mental>

2 "As atuais normas NBR 13.531:1995 e NBR 13.532:1995 foram revistas agrupadas em uma norma única, dividida em três partes... Parte 1 (ABNT NBR 16.636-1), que trata de Diretrizes e Terminologia, e a Parte 2 (ABNT NBR 16.636-2), que se refere ao Projeto Arquitetônico". Disponivel em<https://www.caubr.gov.br/normas-da-abnt-sobre-projetos-arquitetonicosestao-em-consulta-publica-participe/>. Acesso em 23 jun. 2019. 